\title{
Conversations across the table: shared cognition in top management teams
}

\author{
Marian Evans
}

Leicester Castle Business School, De Montfort University, Leicester, UK

Conversations across the table

\begin{abstract}
Purpose - This paper aims to examine the shared mental models (SMMs) of a top management team (TMT) using an emergent perspective in conditions of uncertainty. The paper examines how a TMT conversation represents an emergent cognitive process to reach an action for future planning.
\end{abstract}

Design/methodology/approach - The design uses an emergent SMM approach based on a TMT discussion in an uncertain context. Cognitive mapping techniques illustrate how concepts emerge and are structured. This approach addresses the need for an alternative to aggregate mapping methods and supports the notion of team cognition as an emergent and dynamic process.

Findings - Findings showed that the emergence of a SMM could be elicited and represented using cognitive mapping techniques. Domain knowledge and social relationships supported the emergence of shared knowledge relevant for action on team tasks. A SMM based on team contribution and concept connectivity was identified.

Research limitations/implications - The study is based on data collected from a recorded discussion in a quarterly company meeting, ten days before the UK's original planned exit date, March 2019.

Originality/value - This research study contributes to the SMM and team cognition literature streams by examining the TMT's shared understanding as an emergent process. Empirical studies using cognitive mapping techniques in this context are rare.

Keywords Cognitive mapping, Team cognition, Shared mental models, Emergent process

Paper type Research paper

\section{Introduction}

Policy implications and the impact of Brexit for small- and medium-sized enterprises (SMEs) have posed many critical questions since the June 2016 vote to leave the European Union (EU) (Brown et al., 2019). Brexit is perceived to significantly influence business success, contingent with the level of internationalisation and trade via exports and imports (Balls et al., 2018; Brown et al., 2019). This still presents a potential and worrying obstacle for those internationally aligned SMEs, along with further concerns about future regulatory change, increased import costs and uncertainty regarding access to EU markets. Some of these concerns have been addressed through investment plans and strategic activities (Brown et al., 2019). However, aside from the possible disruption to firm performance and business success, demands are placed on top management teams (TMTs) to make effective decisions based on unknown market changes and requirements.

The aim of this study is to contribute to the literature on shared mental models (SMMs) as an emergent process by using cognitive mapping techniques as a novel approach. Brexit is used as an uncertain, ambiguous and challenging scenario to provide an interesting context. There is a continued need to enrich theoretical understanding of SMMs through empirical research (Mohammed and Dumville, 2001; Mol et al., 2015). Furthermore, there is

Received 7 December 2020 Revised 15 May 2021 Accepted 16 May 2021 
little research that takes an emergent approach using cognitive mapping techniques and TMTs. Understanding how team members represent the exchange of knowledge and experience as an emergent process will contribute towards theoretical development of team cognition and a SMM. In addition, this approach will illustrate how members converse in teams and how collective cognition (Waller et al., 2016) emerges as a SMM structure. The identification of lower-and higher-level components (McGrath et al., 2000; Humphrey and Aime, 2014) will help to deconstruct the underlying dynamics and contributions of knowledge between team members for subsequent performance development of future interactions (Waller et al., 2016).

\section{Theoretical background}

\section{Top management teams and upper echelons theory}

A TMT is defined by Hambrick (2015) as a relatively small group of influential executives at the apex of an organisation, where management is typically a shared activity. The underlying assumption is that team demographics act as a proxy for the cognitive processes that shape decision-making and impacts on strategy in various forms (Carpenter et al., 2004; Abatecola and Cristofaro, 2020). Known as upper echelon (UE) theory, the framework proposed by Hambrick and Mason (1984) states that the enactment of psychological cognitions, values and observable characteristics (such as age, education, career experiences) result in strategic choices. This theory has spawned several decades of research on UE, for example, TMT diversity (Nielsen and Nielsen, 2011), managerial discretion (Wangrow et al., 2015), socio-behavioural and cognitive influences (Bromiley and Rau, 2016) and environmental influences (Yamak et al., 2014).

More recent studies have shown that the UE stream is still a promising one (Carpenter et al., 2004) and that new variables, such as international experience (Carpenter et al., 2001), previous experiences of chief executive officers (CEOs) (Carpenter, 2011) or social networks (Collins and Clark, 2003) are important variables that must be considered. Moreover, recent research has examined personality traits, such as hubris, overconfidence and narcissism (Abatecola and Cristofaro, 2020) or reverse causality (Hambrick, 2007), to establish the sociodemographic features an executive should have. Top executives play a pivotal role in shaping organisational outcomes (Carpenter et al., 2004) but rarely perform in isolation. The "second generation UE model" (Carpenter et al., 2004, p. 759) reflects the significant intervening variables central to the framework as moderators or mediators, one of which is team processes. In line with their recommendations and to move towards recursive and dynamic models, a process approach to SMMs may provide further future opportunities and fruitful insights.

Taking an emergent process approach for observing how a TMT reaches an action outcome provides a different perspective. With this in mind and to empirically approach this proposal cognitive mapping methods are applied. Here, the relationships between the combined effect of behaviours, socio-demographic features and environmental influences can be visualised as explicit representations and cognitively constructed mental models, resulting from team processes and behaviours.

\section{Team cognition}

Larger entrepreneurial organisations are managed and led by teams rather than by individuals (West, 2007), so the way in which a team works together is important for determining the successful performance and outcome of the business (Ensley and Pearce, 2001; Curşeu et al., 2010). The definition of the TMT construct and team membership is generally assumed to be at the senior hierarchical and strategic level of the firm 
(Carpenter et al., 2004). However, as definitions are varied, this research study adopts the broader measure of board and top-level executives, including the CEO (Carpenter et al., 2004).

The emergent dynamic process at team level has been less well examined (Grand et al., 2016). Thus, although prior research has explored team cognition in many different ways, it is surprising that the concept still remains unclear and without agreement on a formal definition (Mol et al., 2015). Most team cognition research uses the terminology "team mental models" or "shared mental models" to represent team members exchange of knowledge and experience as a shared representation (Kneisel, 2020) and learning (Grand et al., 2016). Various types of knowledge are represented (Mohammed and Dumville, 2001), influenced by environmental, organisational, team and individual antecedents (Kraiger and Wenzel, 1997). However, Mol et al. (2015) note that that individual cognition is not the same as team cognition. It is an emergent process (West, 2007; DeChurch and Mesmer-Magnus, 2010; Kneisel, 2020), "from the interplay of the individual cognition of each team member and team process behaviours" (Cooke et al., 2004, p. 4).

According to Mohammed and Dumville (2001), studies on team mental models would benefit from a greater emphasis on discussion and the dynamics of information exchange. Hence, shared understanding and learning can be observed from the outcomes of discussions on strategic issues (Ensley and Pearce, 2001) and the complex interactions between individuals in the team (Mol et al., 2015). Mental models are defined by contextual requirements and constraints (Badke-Schaub et al., 2007) and as TMTs possess distributed and specialised expertise, they must acquire contextual information from each other if they are to reach a fully shared and agreed understanding (Grand et al., 2016). Albeit unconsciously, they will bring to the table their "preconceived and predetermined notions" (Okali and Watt, 2018, p. 3). Similarly, collective representations from previous experience will be stored in the long-term memory and accessed in new meeting situations (Schalk and Curşeu, 2010). As the effectiveness of the task outcome is dependent on the quality of information processing, this highlights the need to assimilate, share and blend internal and external knowledge resources (Chuang et al., 2016) for building collective knowledge structures (Curşeu and Pluut, 2018).

\section{Shared mental models}

Team members use SMMs to represent information about the task, resources required and team member roles for successful collaboration (Redlich et al., 2017). These SMMs are defined as "knowledge structures held by members of a team that enable them to form accurate explanations and expectations for the task" (Cannon-Bowers et al., 1993, p. 221) and "in turn coordinate the actions and adaptive behaviour of the task into other team members' actions" (Zhou and Wang, 2010, p. 434). Viewed as joint comprehension shared by team members (Redlich et al., 2017), the general premise of a SMM is that it improves team effectiveness (Cooke et al., 2004, Schippers et al., 2013; Santos et al., 2016; Kneisel, 2020) and that teams who develop SMMs perform better in defining strategic action and acting on it (DeChurch and Mesmer-Magnus, 2010; Xiang et al., 2013).

However, there are different approaches to the theoretical conceptualisation of the SMM framework (DeChurch and Mesmer-Magnus, 2010; Hensel and Visser, 2019) and a lack of specification on the theoretical lens. According to DeChurch and Mesmer-Magnus (2010), the following three major theoretical perspectives should be considered:

(1) the elicitation method;

(2) the structure of the presentation between team members; and

(3) the representation of emergence.
Conversations across the table 
Previous research has focused more on task knowledge sharedness using experiments or simulations than on content (Curşeu and Pluut, 2018; Kneisel, 2020) and most have disregarded the dynamic and emergent state of team cognition in naturalistic settings. The information-sharing perspective has also emphasised the convergence or similarity of team member knowledge (Mohammed and Dumville, 2001). This study adopts an emergent approach to address this deficit.

There are two types of mental models that may co-exist amongst team members (Cannon-Bowers et al., 1993; Mathieu et al., 2000; Badke-Schaub et al., 2007) based on task and team-related functions. Common empirical categories use Cannon-Bowers et al.'s (1993) proposition of four types: task, equipment, team and team interaction (Badke-Schaub et al., 2007). Three core SMM processes are typically explored: knowledge structures, conflict solving and feedback and team members' interactions (Hensel and Visser, 2019). According to Scheutz et al. (2017), much of the literature on SMMs has focused on quantifying how teams use these models successfully, but seldom how these are operationalised. Furthermore, Grand et al. (2016) note more empirical research is required to demonstrate how this dynamic process emerges from team interaction and the relevance of knowledge sharing and learning as a process. Similarly, the co-creation process is missed (Preller et al., 2016; Hensel and Visser, 2019). In this study, the focus is placed on the process of emergence, in order to address these concerns.

\section{Shared mental models as an emergent phenomenon}

The concept of emergence can be viewed as a bottom-up process, derived from the psychological characteristics, dynamic processes and interactions amongst individuals and teams (Kozlowski and Klein, 2000; Kozlowski et al., 2013). From a conceptual perspective, the emergent phenomenon emanates from a lower level (individual cognition) to a higher level (group cognition) (Kozlowski et al., 2013; Waller et al., 2016). However, the dynamics of emergence is frequently theoretically assumed or examined indirectly in the field (Van den Bossche et al., 2011; Kozlowski et al., 2013). A similar criticism is evident in the SMM literature, where the majority of research focuses on the elicitation method and the structure of presentation rather than on the process of emergence itself (DeChurch and MesmerMagnus, 2010; Hensel and Visser, 2019).

Emergent states are the beliefs that members hold about their goals, abilities and interpersonal norms (Harvey et al., 2019) and develop over time as the team's work unfolds (Marks et al., 2001; Cronin et al., 2011) This has important methodological implications. Firstly, emergent phenomena are the result of cognition, behavioural patterns and structures in a dynamic process (Waller et al., 2016; Hensel and Visser, 2019). Secondly, common research practice measures emergence by eliciting individual team member responses and then aggregating these to group level known as global convergence (Waller et al., 2016, p. 596). The assumption is that group members have homogeneous experiences and similar perceptions. On the other hand, mental model research mostly takes a dispersion approach by assuming heterogeneity, then comparing similarities and differences in knowledge structures. Thirdly, configuration models assume it is neither convergence nor dispersion but examine the structural representation of the responses as a process (Waller et al., 2016, p. 571). However, all three methods have potential shortcomings based on homogeneity and static aggregation (Waller et al., 2016).

A cognitive map facilitates examination of mental representations as a configuration model, in order to "chart the dynamic interaction that gives rise to novel states, patterns and structures" (Waller et al., 2016, p. 572). This process approach to concept emergence (Hensel and Visser, 2019) portrays relationships between concepts and structure as an interactive, 
collaborative process (Redlich et al., 2017; Hensel and Visser, 2019). Thus, a SMM should personify shared understanding as knowledge structures that unite individuals in a team, represented as specific domain knowledge, team task and goals, knowledge about other team members' abilities and team interaction (de Vreede et al., 2012).

\section{Research aims and research question}

The aim of this study is to contribute to the SMM literature by providing an in-depth examination of an emergent process in uncertain conditions using cognitive mapping techniques as a novel approach. Identifying the emergence of a SMM using this technique supports analysis of structures and representations at individual and group level, as well as the nature of emergence as a process and the development of knowledge structures that make up SMMs. The assumption is that cognitive mapping as a bottom-up process will capture the dynamic interactions and concept emergence from individual level to group level, which is collaboratively co-constructed by members as a SMM for the task.

The research question asks the following: How does a SMM emerge and personify shared knowledge structures in a TMT and what insights from this dynamic process can be used to support knowledge sharing and learning as a process?

\section{Methodology}

A qualitative design was applied using cognitive mapping techniques as a suitable approach for addressing the emergence of a SMM. The process of sharing cognitive discourse allowed examination of how individuals in teams think about multiple ideas and create new cognitive schema (Ensley and Pearce, 2001). Shared mental models were conceptualised as team members' overlapping mental representations of key elements (Van den Bossche et al., 2011), represented as clusters that emerged from the mapping process. Mental models specify knowledge content as concepts and relationships (Eden, 2004), so clusters can be regarded as knowledge structures, representing both concepts and relationships. The measurement technique should include both elicitation and representation (Van den Bossche et al., 2011). For this study, cognitive mapping techniques provided the elicitation process, and map composition represented emergent concepts and relationships.

A recorded agenda item conversation between a TMT on Brexit strategy was used. This provided a suitable context for collaborate engagement on a task. The defined agenda item had no definite formulation but provided an open discussion on how the UK company would address the potential problems associated with Brexit policy. However, the goal was to identify major issues and determine appropriate actions.

\section{Cognitive mapping techniques}

Cognitive mapping is a useful tool for examining knowledge structures and cognitive processes (Ho and Wilson, 2008) and for research on strategic cognition (Wrona and Ladwig, 2015). It is a recognised method for illustrating the development of thinking by an individual about a situation (Ensley and Pearce, 2001; Mohammed et al., 2000; Curşeu et al., 2010; Eden and Ackermann, 2010), but can also be applied to teams, reflecting multiple perspectives. Based on text, it is a non-invasive and non-reactive method of data collection (Van den Bossche et al., 2011).

In the map, concepts or categories are graphically represented and linked to each other by relationships (Gómez et al., 2000) elicited through discourse as the result of conscious articulation and expression (Ho and Wilson, 2008). A holistic approach was taken to evaluate team cognition, in contrast to prior studies that have focused on aggregate
Conversations across the table 
methods, as these do not consider social interaction and thus lack construct validity (Curşeu et al., 2010). Thus, exploring team conversations as a cognitive map provides insight into how team members amend, adapt and extend different ideas, resulting in actions that are the outcome of all those involved. In addition, examining the cognitive map as an emergent process allows the researcher to view how individual mental representations overlap to build a SMM. Taking a cognitive mapping approach addresses the criticism that an aggregate method does not consider cognition as an emergent process, observed "from the interplay of the individual cognition of each team member and the team's process behaviours" (Mol et al., 2015, p. 235). Adopting an emergent approach allows for systematic analysis and exploration of emerging concepts and relationships (Ho and Wilson, 2008) with greater explanatory rigour.

\section{Company background and sample}

The company manufactures a product for global distribution and is well known for its innovative developments and leading-edge designs. It was established by two entrepreneurs in 1995 and purchased in 2014 by an international family-held corporate group. The company is now a medium-sized SME, employing approximately 70 full time and 20-30 agency staff. The TMT comprises of five male executives aged between 45 and 65 years, and three different nationalities, representing a convenience sample. All have many years' experience in the sector. An executive from the corporate group was appointed as CEO of the UK based company in 2015 along with one of the original founding entrepreneurs as non-executive director. These five executives in the TMT are responsible for strategy, management and governance of the UK company.

The expertise within the TMT is heterogeneous demonstrating a range of experience, particularly associated with international involvement, global networks and overseas projects in the sector. This international expertise is contingent with the strategic focus of the company. In addition, three members have experience at multiple levels of analysis: team, firm and industry. Two members have worked together since 2004 and have detailed knowledge of the company, its internal workings and established relationships in the market. Between members, the TMT are fluent in five languages.

\section{Data collection}

A qualitative approach was chosen using a recorded, minuted quarterly company meeting agenda item on Brexit, ten days before a planned exit date on March 29, 2019. The agenda item was transcribed into a Word document. The company meeting began with a brief summary of the following four Brexit related issues:

(1) costs of invoicing in sterling compared to euros;

(2) disruption to stock for future planned production;

(3) exchange rates; and

(4) Brexit deal/no deal implications.

The conversation commenced with a discussion on loss of orders caused by potential disruption of raw material stock for planned production. The data was transcribed using NVivo 10 and analysed for coding and interpretation using standard content analysis techniques at sentence level (Cossette, 2002; Eden, 2004; Curşeu, 2008). Sentences and concepts were analysed for relationships and examples are provided in Table 1. 


\begin{tabular}{|c|c|c|c|}
\hline Concept & Example & Relationship & the \\
\hline $\begin{array}{l}\text { Deal/no deal stock (3) } \\
\text { Shelf life (47) }\end{array}$ & $\begin{array}{l}\text { The problem with having lots of stock. . .it } \\
\text { expires... }\end{array}$ & Associative & table \\
\hline Delayed raw material (1) & Would put one month's stock aside... just in case & Causal ( 1 causes 3$)$ & \\
\hline Deal/no deal stock (3) & $\begin{array}{l}\text { there was one week or a fortnight's delay on our } \\
\text { imported critical raw materials }\end{array}$ & & \\
\hline \multirow{3}{*}{$\begin{array}{l}6 \% \text { tariff costs (37) } \\
\text { Negative customer } \\
\text { reaction (38) }\end{array}$} & I think there is no shortcut. We will probably have & \multirow[t]{3}{*}{ Causal (37 causes 38 ) } & \\
\hline & to pay $6 \%$ more... & & \\
\hline & $\begin{array}{l}\text { I think the worst part is how our customers will } \\
\text { react at } 6 \% \text { [increase]. How will these persons react } \\
\text { when they see a lot of papers and } 6 \% \text { more } \\
\text { expensive? }\end{array}$ & & \\
\hline \multirow{3}{*}{$\begin{array}{l}\text { Increased admin for } \\
\text { documentation (60) } \\
\text { New instructions for } \\
\text { customer (59) } \\
\text { Adaptative strategic } \\
\text { planning (35) }\end{array}$} & $\begin{array}{l}\text {...we [would] have to do all the paperwork. For us } \\
\text { it would be like having a new person as all our }\end{array}$ & \multirow[t]{2}{*}{ Causal (60 causes 59) } & \\
\hline & shipments would have to go through with Euro $1 \ldots$ & & Table 1. \\
\hline & $\begin{array}{l}\text {..As a business matter we want to be prepared in } \\
\text { case it happens or not. We will have to adapt; we } \\
\text { will have to plan that as it happens... }\end{array}$ & Chronological & $\begin{array}{r}\text { Examples of concept } \\
\text { identification and } \\
\text { linking relationships }\end{array}$ \\
\hline
\end{tabular}

\section{Constructing the map}

The map was constructed directly from the content analysis and drawn as concepts or statements linked to each other in the order in which they emerged (Cossette, 2002; Eden, 2004; Eden and Ackermann, 2010). Links were based on Gómez et al.'s (2000) categorisations. The tail of the arrow was taken to cause or relate to the statement at the top of the arrowhead. Thus, goal type statements are the desired/not desired outcomes and tails are the options. The completed map depicts a hierarchical structure with desired outcomes at the top of the map, potential outcomes or solutions at the bottom and the main issue in the centre (Eden, 2004).

As the concepts emerged from the conversation, they were written on post it notes as short pieces of text. Each captured as much of the true meaning as possible and were numbered to show the order in which they surfaced. The transcript was checked against the recording and re-read to ensure all statements were correct, as accented grammar was sometimes difficult to understand. Concepts were then arranged and re-arranged to show relationships as links (Eden, 2004) based on linking words and proximity in the text. The arrangement of concepts in the first draft was adjusted to present an easy-to-read final display of the conversation as a twodimensional model, where crossing arrows were kept to a minimum.

This is similar to Carley's (1977) approach, used by Van den Bossche et al. (2011) for measuring SMMs, where texts were first coded as networks of concepts (individual level) and then relationships identified. In this study, relationships were identified between concepts using linking words and by examining text to determine the proximal distance of concepts from each other, known as windowing (Carley, 1977). Next, using map techniques derived from Cossette (2002), concepts and links were arranged to create clusters. In contrast, Carley (1977) compiled individual maps first, then identified concepts and statements that were identical in at least two out of three individual maps for aggregation into a SMM. For this study each emergent cluster was examined to find concept similarity between team members. Using Carley's (1977) method it was noted where the same concept had emerged in the conversation from three or more individual team members (Table 3 ). 


\section{Data analysis}

The data analysis was conducted in three stages. Firstly, concepts, relationships and their connectivity were examined. The map was broad and flat in character and did not represent the more typical teardrop shape that frequently emerges from a problem-solving activity (Figure 1). The cluster identification revealed emergent issues which surfaced as the "nub" of the issue (Eden, 2004). Two key outcomes were identified at the top of the map: "maintaining customer relationship" and "adaptive strategic planning." An action to "establish a reserve stock" was identified at the bottom of the map. Relationships were mostly causal in nature.

Secondly, centrality scores were calculated for each cluster group by counting the number of links between the centre concept in each cluster and its links to other concepts for three levels. This provided a reachability matrix (Cossette, 2002, p. 173) as follows: all concepts directly related to it are worth 1 as first level concepts, second level 0.5 and third level 0.33. All cluster groups with more than five links from itself to other concepts were calculated. The results are shown in Table 2 . Overall map density was calculated using the formula map density $\mathrm{L} / \mathrm{C}(\mathrm{C}-1)$, where $\mathrm{L}=$ links and $\mathrm{C}=$ concept. Altogether, there were 61 concepts and 103 links.

Thirdly, cluster groups with a reachability score higher than 20 and with more than five first level links were examined, as shown in Table 2. In most research, shared cognition is deduced from teams by aggregation of individual representations, where agreement is reached through co-construction (Van den Bossche et al., 2011). The researcher posited that each cluster was an example of dynamic construction as an emergent, collective representation. Hence, concepts and links are built through an open-minded discussion of different perspectives, negotiation and clarification within the group (Van den Bossche et al., 2011). Clusters up to two levels of connectivity were examined to identify the origin of each

Figure 1.

Map structure showing concepts and relationships in their order of emergence

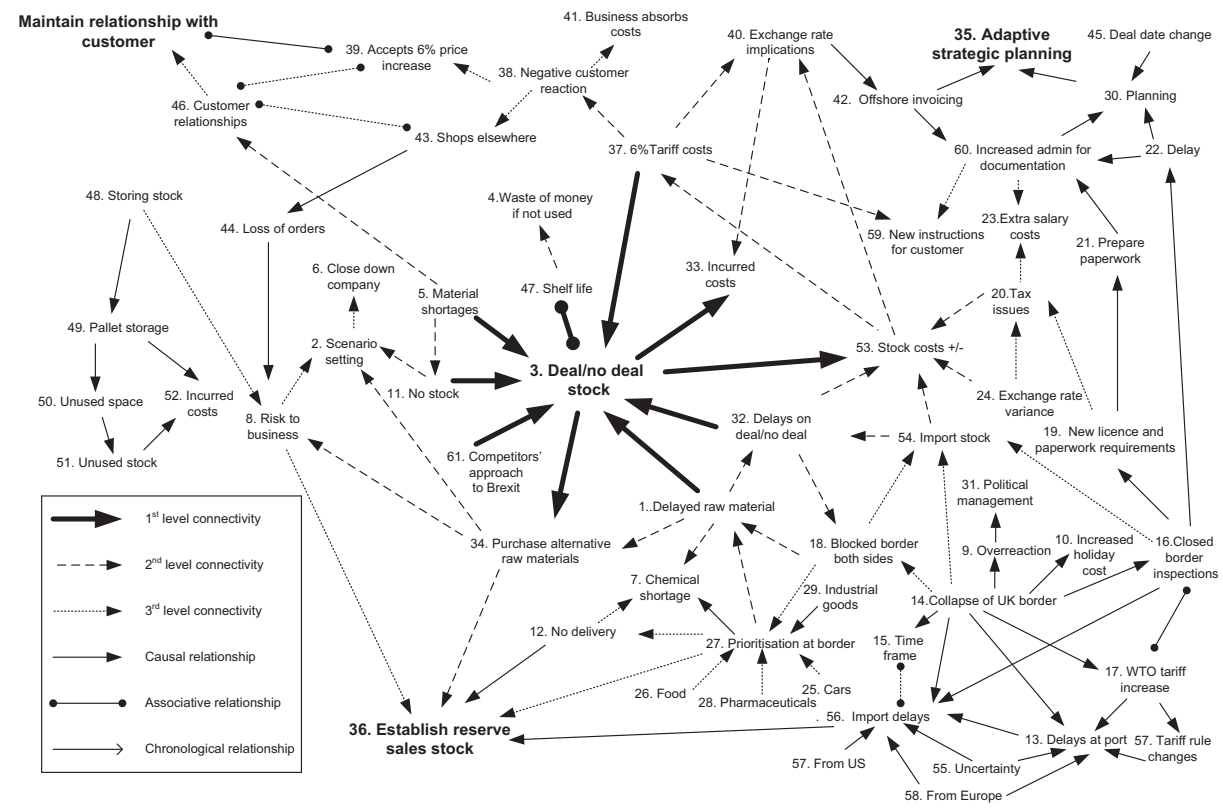


concept, from individual to cluster level as a co-created structure. All figures are in order of emergence for concepts and team member contribution (Table 3).

The analysis of the nub of the problem (Eden, 2004), cluster "deal/no deal stock" as a first level and highly connected cluster, elicited nine shared concepts (highlighted in italics in Table 3). The same procedure was repeated for all clusters in Table 2 and some additional clusters were identified showing three or more member contributions as overlapping knowledge: closed border inspections, import delays, uncertainty and planning. Next, clusters and their links were isolated on the map in order to review structure and positioning. The result produced a SMM (Figure 2). Two clusters, "uncertainty" and "planning" were not linked to this SMM and have not been included in the final model structure. The SMM is made up of three layers of connectivity and all links are causal in nature. This analysis suggests that bottom-up individual concepts converge into clusters as a SMM from information exchange and collaboration between the TMT members, as an agreed action to establish a reserve sales stock.

\section{Results}

General characteristics and map shape

The overall map density at 0.028 suggested that the thinking of the team was not significantly complex, as the map shape was flat rather than hierarchical. A flatter shape demonstrates a high range of choice and many different viewpoints. As map shape determines the relative complexity between nodes and the issue, two ratios are significant: depth vs. width, indicative of depth of detail or width vs depth as a multiplicity of aspects to the issue (Eden, 2004). Thus, the flatter map shape suggested that there were many issues, but none discussed in any depth. In addition, the positions of outcomes and actions were characteristic of map shaping. The importance of maintaining a good relationship with the customer emerged as a strategic outcome. The second outcome was an adaptive strategy based on the uncertainty of potential outcomes from a deal/no deal situation. Both these outcomes were positioned at the top of the map. The emergent action was to establish a reserve stock.

\section{Exploring emergent properties as clusters}

The map structure showed several key cluster groups. A cluster group is a theme of connected nodes and arrows that can be seen in the map as an island (Eden, 2004), for example, "collapse of UK border" or "delay at port." Analysing these cluster groups indicated the robust parts of the map (Eden, 2004) and provided a summary of
Conversations across the table

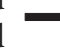




\section{TPM}

Table 3.

Analysis of cluster "deal/no deal stock" at two levels of connectivity to show concept contributions from TMT. Italics indicate similar concept emergence in three or more individuals

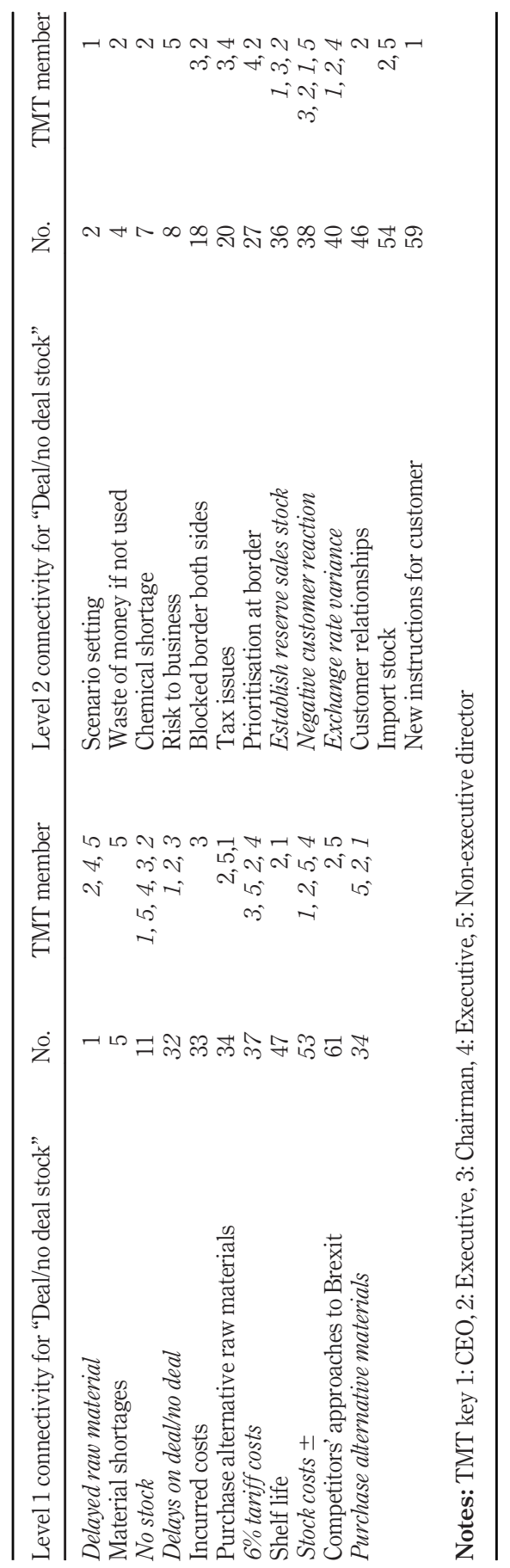




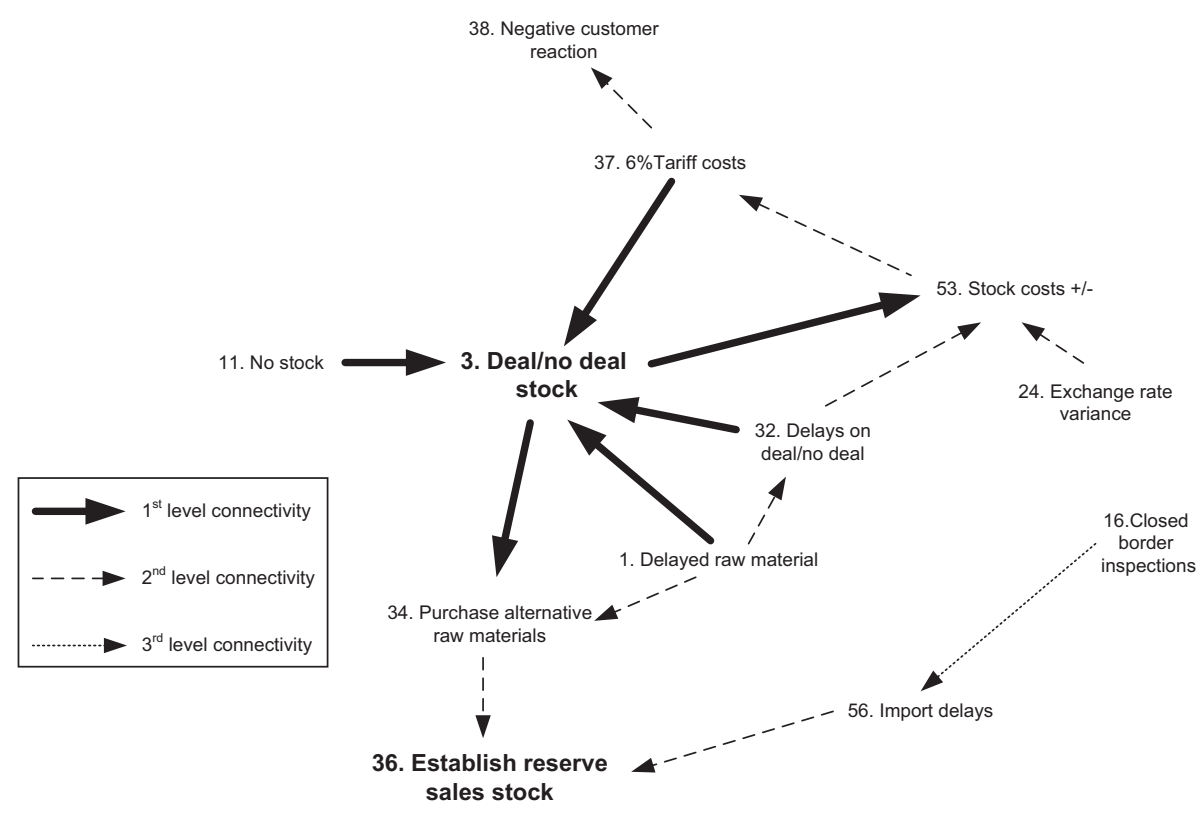

Conversations across the table

Figure 2.

TMT shared mental model

characteristics and complexity. Similarly, the arrangement of clusters and links illustrated the flow of conversation and the connections to concepts in other clusters. This suggests that clusters represent team shared knowledge that has emerged from collaboration on task goals. Moreover, each cluster group indicated specific knowledge, for example, the border clusters (see concepts 14, 16, 18, 27) showed operational and logistical domain knowledge, whereas the increased documentation (see concept 60) showed administration and financial knowledge. These results demonstrate how specialised knowledge is divulged and used by the team. Similarly, the connectivity of these cluster groups shows their relative importance to each other, their integration with other concepts and the different problems addressed in a conversation (Eden, 2004, p. 680).

\section{Cluster connectivity analysis and emergence}

Firstly, each cluster group was analysed by focusing on the links from the concept to other concepts in a specified sequence, where all paths linking the concept to others are considered regardless of their direction (Cossette, 2002). All first level links were highlighted in bold (Figure 1). From these concepts second level links to the next concept were shown as a dashed line. The third level was shown as a dotted line. Centrality scores of each cluster were calculated up to the first three levels. Clusters with the highest centrality score are shown in Table 2.

Four key issues emerged from the centrality scores. These were identified as reserve sales stock (36), stock cost \pm (53), delayed raw material (1) and blocked border (18). The action of establishing a reserve sales stock is not surprising, given its requirement for production. Secondly, the implication of stock costs was an underlying concern, shown by its high connectivity and links to other key clusters. This example indicates how a particular issue or problem may not be openly discussed, but its significance elicited from the connectivity with other cluster groups. Thirdly, delayed raw material and blocked border 
generated feedback loops to other clusters which frequently means dynamic considerations within an issue (Eden, 2004).

Next, the transcript was examined to see how the TMT collaborated and applied their knowledge for shared understanding (see Table 4 for conversation excerpts), using categories outlined by Cannon-Bowers et al. (1993) and de Vreede et al. (2012). The researcher wished to identify whether the emerging concepts in the conversation represented specific domain knowledge, team task and goals, knowledge about other team members' abilities and team interaction categories as recognised theoretical categories in the SMM process (de Vreede et al., 2012). All four categories were identifed from the transcript.

\section{Discussion}

The purpose of the study was to examine the SMMs of a TMT using an emergent perspective and cognitive mapping techniques. The aim of the study was to determine how concepts emerged and were shared as an outcome for strategic action. The research has focused on the emergence of the SMM, how knowledge concepts and clusters are represented and constructed and how findings could be used for future research and practitioner support. The results support a cognitive mapping approach that takes an emergent process, embedded in team processes and sharing content related knowledge (Cooke et al., 2013; Curşeu et al., 2010; DeChurch and Mesmer-Magnus, 2010; Mol et al., 2015). The TMT used a combination of prior experience and confidence in each other's narrative

Shared understanding of the team task and goal (30. Planning)

Domain knowledge (53. Stock costs \pm )

Knowledge about other team members' abilities, knowledge and skills to perform (53. Stock costs $\pm)$

Interaction between team members to collaborate with relevant information and ideas on identified problem (14. Collapse of UK border)

\section{Table 4.}

Excerpts from the transcript showing concept identification and SMM processes
TM3: When it happens, as a business matter, we want to be prepared in case it happens or not.

TM5: It's like a poker game, we don't know.

TM3: It's not whether this happens or not, we need to prepare for this. TM4: To me it may happen, but to my mind it makes it difficult to see if this will happen.

TM3: I guess if it [euro] collapses, let's say it goes down by $20 \%$, it happened once with the Swiss Franc, but what happens then we have to increase prices then in the UK? But I think the UK people are used to absorbing price increases because we did that in the last 18 months for different prices, not only me, but the industry too. So, it definitely would be first of April, first of May for new prices.

TM2: So, if we increase our stock or not, we have 2 weeks?

TM4: How much will this cost, $£ 10,000$ ?

TM1: No $£ 11,000$, let me check first, it may be postponed and then postponed again. I'll send the email now, we should be okay 5-8 $8^{\text {th }}$ March, we can start then, let me check that, we can only be positive.

TM4: The Euro will collapse in the UK in one week? A few days, no goods at all? I think this because. . .

TM5: They say that for a standard inspection they would have to do it against WTO.

TM2: That's why it will collapse.

TM4: It will not happen, I think they will collapse the boundary, the UK [boundary], if not, they will be crazy to [let it happen].

TM1: On one day they will stop these instructions.

TM2: I think that we need that 12,000 (reserve stock) because they will collapse [it], they will collapse. I'm pretty sure about that, but for sure, not for a long time because they may find a way...

Notes: TMT key 1: CEO, 2: Executive, 3: Chairman, 4: Executive, 5: Non-executive director 
and beliefs, which helped them to interpret and process information for shared knowledge and strategic outcomes in response to Brexit.

The concepts that emerged from the mapping process implied that the TMT were primarily concerned with disruption to trade and the need to mitigate import problems resulting from border delays. These are clearly represented in the conceptual structure of the SMM in Figure 2. Maintaining a frictionless and borderless trade for SMEs is a chief concern (FSB, 2017) as well as the potential impact of tariffs and customs control administration post Brexit (Balls et al., 2018). This study's research has supported recent research on Brexit, where the impact on SMEs has received much less attention than larger companies (Barron and Boutary, 2021).

The concept of shared team cognition is defined by Ensley and Pearce (2001) as a situation in which two or more team members have some degree of common knowledge. The map analysis showed that the contribution of domain knowledge as shared knowledge was more evident amongst those who had local and international industry sector experience. As individuals acquire knowledge and understanding, they integrate new knowledge with existing information, so this observation was not surprising, as their experience would contribute towards this process. However, the type of information shared, and the way it is communicated also influences how team members integrate this for understanding (CannonBowers et al., 1993; Grand et al., 2016). As the conversation emerged, knowledge sharing was observed in several instances during the discussion, for example, several concepts on UK border issues (see 13, 14, 16, 18, 56) elicited many different concepts, providing a variety of perspectives and experiences to support different viewpoints for exploration of options.

Similarly, collective knowledge was observed emerging from TMT members' domain knowledge and prior experience, for example, the concept "increased administration" (concept 60) emerged from several smaller clusters which drew on financial knowledge, customer relationships and conflict between different viewpoints on a potential border collapse. This illustrates the benefits of taking an emergent process, where concepts and links can be tracked back and aligned to specific knowledge and beliefs. Mapping techniques make a useful contribution to understanding dialogue and knowledge transfer, as they indicate distribution of specialised individual knowledge in the team and provide insights how this knowledge is shared and constructed. As a team only performs well when its team members have sufficient specialised knowledge about the task (Curşeu et al., 2010, p. 1260), such insights are invaluable for performance management and aligning expertise for strategic decision-making in top teams.

Analysis of map connectivity gave a deeper insight into this process. The emergence of concepts showed that a focus on negative operational issues and scenarios was introduced at the start of the conversation, based on weak cause and effect relationships and associations, for example, close down the company (6), waste of money (4) or shortages (5), before a more collaborative approach was adopted. Specific domain knowledge, such as tool/ equipment (Badke-Schaub et al., 2007) and performance requirements also emerged at this early stage. This suggests an airing of individual viewpoints before a shared understanding of the task commenced, associated with awareness of the characteristics and beliefs of the team members (Santen et al., 2009).

The clusters and connectivity analysis suggests that a co-construction process emerged from individual to group level (Kozlowski et al., 2013; Waller et al., 2016). Clusters were compiled from a linear emergent sequence as a simple accumulation of individual contributions, where one concept emerged after the next. However, the links to other concepts were not always represented as a sequential emergent process, as connectivity spanned multiple links with other concepts and clusters. According to Jeong and Chi (2007), 
reaching a shared cognition interpretation is very challenging as acknowledgement of contribution must include active integration and be agreed to be shared. Hence, team members may only build on their own mental model. Nevertheless, the analysis of cluster group contributions (Table 3) suggests that the cluster "deal/no deal stock," for example, was co-constructed and causally linked with an action to establish a reserve sales stock. Similarly, the cluster "closed border inspections" was also causally linked to this, suggesting active integration and agreed action. Both these form part of the final SMM shown in Figure 2.

In addition, the other two cluster concepts identified, uncertainty and planning, may represent the beginning of a co-creation process but did not reach an agreement stage. Further analysis of the smaller surrounding clusters may throw light on this observation and whether these were examples of small SMMs that were building blocks for other clusters, or just isolated novel clusters representing other issues that were implicit and were not agreed for action. Examples like this are potential areas for future discussion, or representative of underlying issues that must be addressed in further meetings.

Furthermore, the emerging concepts in the first half of the conversation were linked to the higher connectivity cluster groups. This suggests that the initial part of the conversation established a foundation for knowledge exchange at an individual level and the subsequent discourse was the result of sharing knowledge for cluster connectivity, thus moving from individual to a higher group level of shared collective cognition (Kozlowski et al., 2013; Waller et al., 2016). According to Mohammed and Dumville (2001), team models bring explanatory power to teams by directly impacting team processes and enabling members to formulate accurate teamwork and taskwork predictions and performance.

The distribution of expertise amongst the team members, the level of confidence each had in each other's expertise, as well as sensitivity to social influence and leadership are considered to influence how mental models emerge (Grand et al., 2016). This implies that characteristics and behaviours of individuals shape emergent outcomes. In this study, some contributions may have been influenced by the hierarchical nature of a family-owned business. However, it was noted that in spite of language differences, the TMT adjusted to differences in interpretations and values which did not negatively impact on collaborative outcomes or teamwork functions (Heldal et al., 2020). This suggests the adaptive strategic planning (concept 35) was a result of skilful communication and drawing together of salient concepts that emerged during the conversation for future options.

Comprehensive domain knowledge was shared for coordination of key issues during the discussion. The discussion on border issues illustrated depth of detail, feedback loops and links to other important clusters through second and third level connections, before the consensus for agreed action on establishing a reserve sales stock was reached. Here, performance was based on the ability and credibility of belief in others' knowledge and information and used for guiding behaviour (DeChurch and Mesmer-Magnus, 2010). The emergent process also indicated key drivers in the team's dynamic interplay. It was observed how one member prompted exploration of multiple options by asking challenging questions, the outcome of which facilitated strategic consensus. Thus, in spite of exploring issues by taking an analytical stance with a focus on cause-effect relationships, a more critical viewpoint prompted some conflict, but this helped to surface relevant, prior experience for shared understanding.

Conflict in conversations can result in a lack of cohesion and a potential mismatch between shared understanding and the flexibility to adapt and adjust (Curşeu and Schruijer, 2018). This is important, as misunderstandings and misinterpretations can trigger affective responses (Ensley and Pearce, 2001), which suggests that such responses may disrupt the 
flow of emerging representations and distort the development of cluster groups. However, in this study, case conflict was handled effectively by one member who moved the conversation forward and out of the conflict arena. It was interesting to note that the same member was frequently the negotiator in the more difficult conversations and skilfully brought key clusters back into the conversation through the use of feedback loops. This illustrates how specialised social skills may be applied to develop and support relationships during the process, despite cultural differences.

Overall, the findings support the use of cognitive mapping techniques to elicit knowledge structures for assessing behaviour and performance (DeChurch and Mesmer-Magnus, 2010) and how the process of emergence demonstrates structural relationships at individual and group level. The results show that cognitive mapping is a fruitful method for representing an emergent process, where team members' knowledge exchange can be displayed as a shared representation (Grand et al., 2016; Kneisel, 2020). In addition, deconstructing clusters shows knowledge contribution and how it is used in SMMs as an emergent process (West, 2007; DeChurch and Mesmer-Magnus, 2010; Kneisel, 2020). The connectivity and contribution analysis allowed the interplay between individual and group cognition to be observed, as well as process behaviour (Cooke et al., 2004, p. 4). The emergent process will support the identification of the four category types (Cannon-Bowers et al., 1993; BadkeSchaub et al., 2007). Despite a focus on knowledge structures as a core process (Hensel and Visser, 2019), the mapping methodology provides a suitable window into the "cognitive space" by explicitly showing how SMMs emerge and are structured in a task situation.

The emergent process has several benefits for practitioners as it can be used to identify key players in the process and highlight any mental model processes that are inadequate or that can be changed through learning. Firstly, it provides a fine-grained analysis of the TMT mental representations, which provides insight on team interaction, how their knowledge is used and how conflict and feedback are managed in the group. It shows whether the team is operating at a group level, or just purely exchanging knowledge that adds to their individual mental models. Deconstructing clusters for contribution analysis would highlight any discrepancies and deficiencies in sharing knowledge. For team effectiveness to improve, then sharedness is paramount as members must acquire contextual information from each other if they are to reach a fully shared and agreed understanding (Grand et al., 2016). Understanding the cognitive contribution within a team, as shared or overlapping knowledge is proven to increase team effectiveness. Secondly, it shows how decisions are framed, shared, negotiated and agreed for action. In terms of TMT skills, these are needed for strategic planning and problem-solving. Improving understanding of this will assist team effectiveness and enable support systems, such as measurement or performance appraisal (DeChurch and MesmerMagnus, 2010), to develop personal and team effectiveness.

\section{Strengths, limitations and directions for future research}

The strength of this study lies in the exploration of a SMM as an emergent process, as it has demonstrated how representations of a TMT can be shaped as a SMM. This goes part way to addressing how a SMM is operationalised (Scheutz et al., 2017). Hence, this makes a valuable contribution to the SMM literature as it addresses the need for an alternative to aggregate methods, deemed critical for developing the field of group cognition (Cooke et al., 2013). It provides a methodological framework that can be adapted for future emergent research in this context. It shows that the dynamics of information exchange and the development of SMMs can be examined without the need for an aggregate approach and that cognitive mapping techniques are a fruitful method for representing this dynamic, emergent process (Grand et al., 2016). As the SMM concept for understanding shared 
cognitions in TMTs has been seldom used (Heldal et al., 2020), this study provides a new perspective.

There are several limitations to this study. Firstly, collecting data at more than one time point would improve the limitations of a cross-sectional design by showing how an emergent process can develop over a much longer period or over multiple meetings. This would provide further empirical evidence concerning the dynamics of shared knowledge, the emergent process and how this is influenced by different contextual variables. Secondly, further empirical research is needed to explore the notion of concept sharedness and the source of contributions from members as an emergent process, and how this is used to inform action as the narrative evolves. The research study did not explore this in different contexts nor used multiple data sets. However, in contrast to the more typical aggregate approach, the study has highlighted the need to view shared cognition as an emergent, dynamic process for future research. Thirdly, results from this study cannot be generalised, so further empirical work using this methodology is needed to explore TMT in different settings and where their SMMs are examined as an emergent process.

\section{References}

Abatecola, G. and Cristofaro, M. (2020), "Hambrick and Mason's 'upper echelons theory': evolution and open avenues", Journal of Management History, Vol. 26 No. 1, pp. 116-136.

Badke-Schaub, P., Neumann, A., Lauche, K. and Mohammed, S. (2007), "Mental models in design teams: a valid approach to performance in design collaboration?”, CoDesign, Vol. 3 No. 1, pp. 5-20.

Balls, E., Sands, P., Hallam, E., Leape, S., Sethi, M. and Weinberg, N. (2018), "Time for clarity: the views of British business on the path to Brexit", (M-RCBG Working Paper Series, No 84) Cambridge, MA: Harvard Kennedy School, available at www.hks.harvard.edu/sites/default/files/centers/ mrcbg/working.papers/84_Harvard\%20Working $\% 20$ PaperTime $\% 20$ for $\% 20$ ClarityFinPAS.pdf (accessed 14 September 2020).

Barron, A. and Boutary, M. (2021), "The Brexit Dilemma for small business: European companies respond", Journal of Business Strategy, Vol. 42 No. 3, pp. 196-205.

Bromiley, P. and Rau, D. (2016), "Social, behavioural and cognitive influences on upper echelons during strategy process: a literature review", Journal of Management, Vol. 42 No. 1, pp. 174-202.

Brown, R., Linares-Zegarra, J. and Wilson, J.O.S. (2019), "The (potential) impact of Brexit on UK SMEs: regional evidence and public policy implications”, Regional Studies, Vol. 53 No. 5, pp. 761-770.

Cannon-Bowers, J.A., Salas, E. and Converse, S. (1993), "Shared mental models in expert team's decision making", in Castellan, N.J. (Ed.), Individual and Group Decision Making: Current Issues, Lawrence Erlbaum Associates, Hillsdale, NJ.

Carley, K.M. (1977), "Extracting team mental models through textual analysis", Journal of Organizational Behavior, Vol. 18 No. 1, pp. 533-558.

Carpenter, M.A. (2011), Handbook of Top Management Team Research, Edward Elgar Publishing, New York, NY.

Carpenter, M.A., Geletkanycz, M.A. and Sanders, W.G. (2004), "Upper echelons research revisited: antecedents, elements and consequences of top management team composition", Journal of Management, Vol. 30 No. 6, pp. 749-778.

Carpenter, M.A., Sanders, W.G. and Gregerson, H.B. (2001), "Bundling human capital with organisational context: the impact of international assignment experience on multinational firm performance and CEO pay", Academy of Management Journal, Vol. 44, pp. 493-512.

Chuang, C.-H., Jackson, S.E. and Jiang, Y. (2016), "Can knowledge-intensive teamwork be managed? Examining the roles of HRM systems, leadership, and tacit knowledge", Journal of Management, Vol. 42 No. 2, pp. 524-554. 
Collins, C.J. and Clark, K.D. (2003), "Strategic human resource practice, top management team social networks and firm performance: the role of human resource practices in creative organisational competitive advantage", Academy of Management Journal, Vol. 46, pp. 720-660.

Cooke, N.J., DeJoode, J.A., Pedersen, H.K., Gorman, J.C., Connor, O.O. and Kiekel, P.A. (2004), "The role

Conversations across the table of individual and team cognition in uninhabited air vehicle command-and-control", Technical Report for AFOSR Grant Nos. F49620 - 01-1-0261 and F49620-03-1-0024.

Cooke, N.J., Gorman, J.C., Myers, C.W. and Duran, J.L. (2013), "Interactive team cognition”, Cognitive Science, Vol. 37 No. 2, pp. 255-285.

Cossette, P. (2002), "Analysing the thinking of F. W. Taylor using cognitive mapping”, Management Decision, Vol. 40 No. 2, pp. 168-182.

Cronin, M.A., Weingart, L.R. and Todorova, G. (2011), "Dynamics in groups: are we there yet?", Academy of Management Annals, Vol. 5 No. 1, pp. 571-612.

Curşeu, P.L. and Pluut, H. (2018), "A systematic investigation of absorptive capacity and external information search in groups. implications for group cognition", Team Performance Management: An International Journal, Vol. 24 Nos 7/8, pp. 411-434.

Curşeu, P.L. and Schruijer, S. (2018), "Cross-level dynamics of collaboration and conflict in multi-party systems: an empirical investigations using a behavioural simulation", Administrative Sciences, Vol. 8 No. 3, pp. 1-14.

Curşeu, P.L., Schalk, R. and Schruijer, S. (2010), "The use of cognitive mapping in eliciting and evaluating group cognitions", Journal of Applied Social Psychology, Vol. 40 No. 5, pp. 1258-1291.

Curşeu, P., Vermeulen, P.A.M. and Bakker, R.M. (2008), "The psychology of entrepreneurial strategic decisions", in Vermeulen, P.A.M. and Curşeu, P.L. (Eds), Entrepreneurial Strategic DecisionMaking, Edward Elgar, Cheltenham, pp. 68-86.

de Vreede, T., Boughzala, I., deVreede, G. and Rieter-Palmon, R.A. (2012), "A model and exploratory field study on team creativity", 2012 45th HI International Conference on System Science (HICSS), (2012) pp. 227-236.

DeChurch, L.A. and Mesmer-Magnus, J.R. (2010), "The cognitive underpinnings of effective teamwork: a meta-analysis", Journal of Applied Psychology, Vol. 95 No. 1, pp. 32-53.

Eden, C. (2004), "Analysing cognitive maps to help structure issues or problems", European Journal of Operational Research, Vol. 159 No. 3, pp. 673-686.

Eden, C. and Ackermann, F. (2010), "Chapter 9: decision making in groups: theory and practice", in Nutt, P.C. and Wilson, D.C. (Eds), Handbook of Decision Making, Wiley and Sons Ltd, NJ, pp. 231-272.

Ensley, M.D. and Pearce, C.L. (2001), "Shared cognition in top management teams: implications for new venture performance", Journal of Organizational Behavior, Vol. 22 No. 2, pp. 145-160.

Federation of Small Businesses, (FSB) (2017), Keep Trade Easy: What Small Firms Want Form Brexit, Brexit Research Series, FSB, London.

Gómez, A., Moreno, A., Pazos, J. and Sierra-Alonso, A. (2000), "Knowledge maps: an essential technique for conceptualization”, Data and Knowledge Engineering, Vol. 33 No. 2, pp. 169-190.

Grand, J.A., Kuljanin, G., Braun, M.T., Kozlowski, S.W.J. and Chao, G.T. (2016), “The dynamics of team cognition: a process-oriented theory of knowledge emergence in teams", Journal of Applied Psychology, Vol. 101 No. 10, pp. 1353-1385.

Hambrick, D.C. (2007), "Upper echelons theory: an update", Academy of Management Review, Vol. 32 No. 2, pp. 334-343.

Hambrick, D.C. (2015), “Top management teams”, in Cooper, C.L., Flood, P.C. and Freeney, Y. (Eds), Wiley Encyclopedia of Management, available at: https://doi.org/10.1002/9781118785317.weom110276

Hambrick, D.C. and Mason, P.A. (1984), "Upper echelons: the organisation as a reflection of its top managers", Academy of Management Review, Vol. 9 No. 2, pp. 193-206. 
Harvey, J.-F., Leblanc, P.-M. and Cronin, M.A. (2019), "Beyond separate emergence: a systems view of team learning climate", Organisational Psychology, p. 1441.

Heldal, F., Sjøvold, E. and Stålsett, K. (2020), "Shared cognition in intercultural teams: collaborating without understanding each other", Team Performance Management: An International Journal, Vol. 26 Nos 3/4, pp. 211-226.

Hensel, R. and Visser, R. (2019), "Explaining effective team vision development in small entrepreneurial teams: a shared mental models' approach", Journal of Small Business Strategy, Vol. 29 No. 01, pp. 1-15.

Ho, M. and Wilson, M. (2008), Cognitive Mapping Methodologies for Entrepreneurial Cognition Research, AGSE, 2008, pp. 311-324.

Humphrey, S.E. and Aime, F. (2014), "Team microdynamics: toward an organising approach to teamwork", Academy of Management Annals, Vol. 8 No. 1, pp. 443-503.

Jeong, H. and Chi, M.T.H. (2007), "Knowledge convergence and collaborative learning", Instructional Science, 2007, Vol. 35 No. 4, pp. 287-315.

Kneisel, E. (2020), "Team reflections, team mental models and team performance over time", Team Performance Management: An International Journal, Vol. 26 Nos 1/2, pp. 143-168.

Kozlowski, S.W.J. and Klein, K.J. (2000), "From micro to meso: critical steps in conceptualizing and conducting multilevel research", Organizational Research Methods, Vol. 3, pp. 211-236.

Kozlowski, S.W., Chao, G.T., Grand, J.A., Braun, M.T. and Kuljanin, G. (2013), "Advancing multilevel research design capturing the dynamics of emergence", Organizational Research Methods, Vol. 16 No. 4, pp. 581-615.

Kraiger, K. and Wenzel, L.H. (1997), "Conceptual development and empirical evaluation of measures of shared mental models as indicators of team effectiveness", in Brannick, M.T., Salas, E. and Prince, C. (Eds), Series in Applied Psychology. Team Performance Assessment and Measurement: Theory, Methods, and Applications, Lawrence Erlbaum Associates Publishers, pp. 63-84.

McGrath, J.E., Arrow, H. and Berdahl, J.L. (2000), "The stuff of groups: past, present and future", Personality and Social Psychology Review, Vol. 4 No. 1, pp. 95-105.

Marks, M.A., Mathieu, J.E. and Zaccaro, S.J. (2001), "A temporally based framework on taxonomy of team processes”, Academy of Management Review, Vol. 26 No. 3, pp. 356-376.

Mathieu, J.E., Goodwin, G.F., Heffner, T.S., Salas, E. and Cannon-Bowers, J.A. (2000), "The influence of shared mental models on team processes and performance", Journal of Applied Psychology, Vol. 85 No. 2, pp. 273-283.

Mohammed, S. and Dumville, B.C. (2001), "Team mental models in a team knowledge framework: expanding theory and measurement across disciplinary boundaries", Journal of Organizational Behavior, Vol. 22 No. 2, pp. 89-106.

Mol, E., Khapova, S.N. and Elfring, T. (2015), "Entrepreneurial team cognition: a review”, International Journal of Management Reviews, Vol. 17 No. 2, pp. 232-255.

Nielsen, B.B. and Nielsen, S. (2011), "The role of top management team orientation in strategic decision making: the choice of foreign entry mode", Journal of World Business, Vol. 46 No. 2, pp. 185-193.

Okali, J. and Watt, J. (2018), "Crisis decision-making: the overlap between intuitive and analytical strategies", Management Decision, Vol. 56 No. 5, pp. 1122-1134.

Preller, R., Breugst, N. and Patzelt, H. (2016), "Do we all see the same future? Entrepreneurial team members visions and opportunity development", Academy of Management Proceedings, Vol 1, p. 113642, Academy of Management, Briarcliff Manor, N.Y.

Redlich, B., Siemon, D., Latterman, C. and Robra-Bissantz, S. (2017), "Shared mental models in creative virtual teamwork", Proceedings of the 50th HI International Conference of Systems Sciences.

Santen, W., van Jonker, C. and Winjgaards, N. (2009), "Crisis decision making through a shared integrative negotiation mental model”, International Journal of Emergency Management, Vol. 6 Nos 3/4, pp. 342-355. 
Santos, C.M., Passos, A.M. and Uitdewilligen, S. (2016), "When shared cognition leads to closed minds: temporal mental models, team learning, adaptation and performance", European Management Journal, Vol. 34 No. 3, pp. 258-268.

Schalk, R. and Curşeu, P.L. (2010), "Cooperation in organisations", Journal of Managerial Psychology, Vol. 25 No. 5, pp. 453-459.

Scheutz, M., DeLoach, S.A. and Adams, J.A. (2017), “A framework for developing and using shared mental models in human-agent teams", Journal of Cognitive Engineering and Decision Making, Vol. 11 No. 3, pp. 203-224.

Schippers, M., Homan, A.C. and van Knippenberg, A. (2013), "To reflect or not to reflect; prior team performance as a boundary condition of the effects of reflexivity on learning and final team performance", Journal of Organizational Behavior, Vol. 34 No. 1, pp. 6-23.

Van den Bossche, P., Gijselaers, W., Seger, M., Woltjer, G. and Kirschner, P. (2011), "Team learning: building shared mental models", Instructional Science, Vol. 39 No. 3, pp. 283-301.

Waller, M.J., Okhuysen, G.A. and Saghafian, M. (2016), “Conceptualizing emergent states”, Academy of Management Annals, Vol. 10 No. 1, pp. 561-598.

Wangrow, D.B., Schepker, D.J. and Barker, V.L. III (2015), "Managerial discretion: an empirical review and focus on future directions", Journal of Management, Vol. 41 No. 1, pp. 99-135.

West, G.P. III, (2007), "Collective cognition: when entrepreneurial teams, not individuals, make decisions", Entrepreneurship Theory and Practice, Vol. 31 No. 1, pp. 77-102.

Wrona, T. and Ladwig, T. (2015), "Studying strategy formation in small companies - a cognitive perspective", Journal of Strategy and Management, Vol. 8 No. 1, pp. 2-20.

Xiang, C., Lu, Y. and Gupta, S. (2013), "Knowledge sharing in information system development teams: examining the impact of shared mental model from a social capital theory perspective", Behaviour and Information Technology, Vol. 32No No. 10, pp. 1024-1040.

Yamak, S., Neilsen, S. and Escribá-Esteve, A. (2014), "The role of external environment in upper echelons theory: a review of existing literature and future research directions", Group and Organization Management, Vol. 39 No. 1, pp. 69-109.

Zhou, Y. and Wang, E. (2010), "Shared mental models as moderators of team process performance relationships", Social Behaviour, Vol. 38 No. 4, pp. 433-444.

\section{Further reading}

Curşeu, P.L. and Schruijer, S.G.L. (2017), "Stakeholder diversity and the role of comprehensiveness of sustainability decisions: the role of collaboration and conflict", Current Opinion in Environmental Sustainability, Vol. 28, pp. 114-120.

\section{Corresponding author}

Marian Evans can be contacted at: marian.evans@dmu.ac.uk

For instructions on how to order reprints of this article, please visit our website: 